\title{
Characterization of the stress-strain state in a gas turbine engine compressor disc taking into account damage accumulation
}

\author{
Natalia Boychenko, Ivan Ishtyryakov \\ Institute of Power Engineering and Advanced Technologies, FRC Kazan Scientific Center, Russian Academy of Sciences, Russia \\ nataboi@ya.ru,ivan_200999@mail.ru
}

\begin{abstract}
A stress-strain state analysis of a gas turbine engine compressor disc was conducted with consideration to the accumulation of damages under various loading conditions in the temperature range.

Characterization of constraint effects was performed using the local stress triaxiality $h, T_{Z}$-factor and $I_{n}$-factors for various crack sizes and different operation conditions.

The distributions of elastic, plastic and creep stress intensity factors were determined by numerical calculation. Results for several crack front positions, temperature values and disc rotation angular velocity were obtained.

The differences in the behaviour of elastic and nonlinear fracture resistance parameters were observed on the basis of loading conditions, crack geometry and temperature. Nonlinear stress intensity factors are preferred as the fracture resistance parameters of materials and structures.
\end{abstract}

KeYwords. Compressor disc; Creep; Damage; Surface flaw; Plastic stress intensity factor; Creep stress intensity factor.

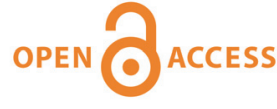

Citation: Boychenko N., Ishtyryakov I., Parametric study of stress-strain state in gas turbine engine compressor disc taking into account damage accumulation, Frattura ed Integrità Strutturale, 50 (2019) 54-67.

Received: 28.05 .2019

Accepted: 07.07.2019

Published: 01.10.2019

Copyright: (C) 2019 This is an open access article under the terms of the CC-BY 4.0, which permits unrestricted use, distribution, and reproduction in any medium, provided the original author and source are credited.

\section{INTRODUCTION}

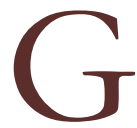
as turbine engines (GTE) are the main power plants in modern aviation. Many types of engines in land and marine engineering are based on GTEs. GTEs are operated under extremely high temperatures and loads for long periods of time. The temperature ranges from $-60^{\circ} \mathrm{C}$ to $+1700^{\circ} \mathrm{C}$, air pressure can reach $300 \mathrm{MPa}$, and gas flow rate exceeds the sonic velocity. The main loads are derived from centrifugal forces on the rotating parts of the rotor; a rotation frequency reaches $5000 \mathrm{1} / \mathrm{s}$, and the circumferential speed is $-450 \mathrm{~m} / \mathrm{s}$. High-strength materials, efficient technological processes and advanced design solutions are used to implement highly reliable parameters.

Titanium alloys and stainless steels are often used for highly loaded rotor components, and heat-resistant nickel-based alloys are used for high-temperature turbine components [1,2].

When in operation, the discs subjected to centrifugal and thermal loads are the most loaded part of the rotors. The compressor disc has various concentrators in the form of grooves, holes, mating surfaces and recesses, etc. In some cases, stresses near concentrators may exceed the yield strength, and plastic stains will occur [3, 4]. 
This study aims to explore elastic and nonlinear fracture resistance parameters and analyse constraint parameters taking into account accumulation of damages under various loading conditions within a temperature range.

\section{THE SUBJECT UNDER STUDY AND MATERIAL PROPERTIES}

$\mathrm{I}$ $\mathrm{n}$ this study, the stress-strain state and the fracture resistance parameters in an aircraft GTE compressor disc (Fig. 1a) were analysed. Slot fillets under the blade are the concentrated stress areas in the compressor disc of the aircraft GTE [3, 5-7]. The 'dovetail' type attachment had a broach angle of $26^{\circ}$ at the axis of rotation, and partial-through surface cracks occurred in the disc and blade attachment [7, 8-10] (Fig. 1b). The crack propagation usually starts from a quarter elliptical corner surface flows $[9,11]$. Crack developed in slot fillet near the disc outer surface. Further, the growing crack intersected the entire thickness of the disc. As a result, the disc rim ruptured (Fig. 1c) $[9,11]$.

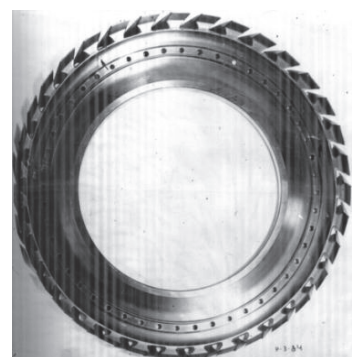

a)

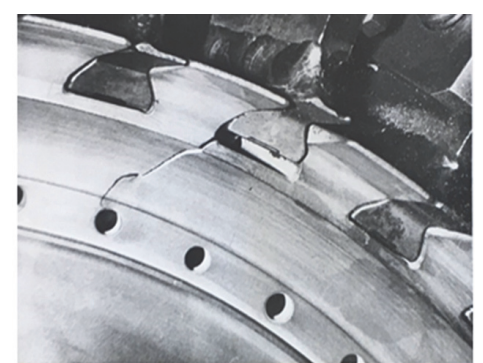

b)

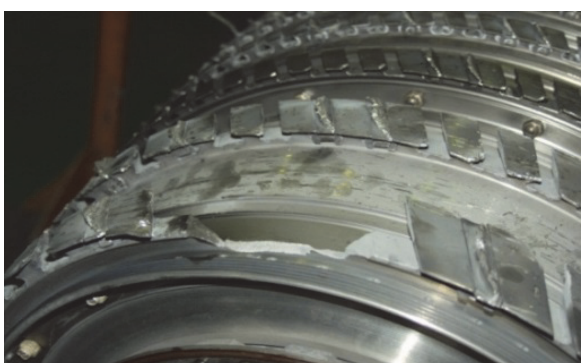

c)

Figure 1: GTE compressor disc (a) and operation damages of disc and «dovetail type» blade attachment (b, c).

Numerical analyses of the stress-strain state under the operating loading conditions were conducted in this study at various temperatures and crack sizes.

The first part of numerical calculations focused on the stress-strain state analysis of the compressor disc without cracks. The second part was devoted to the analysis of the compressor disc with operational damage in the slot fillet of the 'dovetail' type disc and its blade attachments. Three types of curvilinear crack geometry were considered.

All calculations were performed at room $\left(23^{\circ} \mathrm{C}\right)$ and elevated $\left(300^{\circ} \mathrm{C}\right.$ and $\left.370^{\circ} \mathrm{C}\right)$ temperatures with a rotor angular velocity of 925 and $1000 \mathrm{rad} / \mathrm{sec}$. Elastic, plastic and creep conditions were considered. Damage accumulation was analysed in consideration of creep conditions.

Thus, numerical investigations were performed for given combinations of the main parameters, such as the angular velocity of the compressor disc, temperature, shape and size of the defect and the elastic, plastic and creep properties of the material. The combinations of the parameters used in the numerical calculations are presented in Tab. 1.

\begin{tabular}{|c|c|c|c|c|c|c|c|c|c|}
\hline \multirow{3}{*}{$\begin{array}{l}\text { Angular } \\
\text { velocity, } \\
\mathrm{rad} / \mathrm{s}\end{array}$} & \multirow{3}{*}{$\begin{array}{c}\text { Temp., } \\
{ }^{\circ} \mathrm{C}\end{array}$} & \multirow{2}{*}{\multicolumn{4}{|c|}{ Disc without crack }} & \multirow{2}{*}{\multicolumn{4}{|c|}{$\begin{array}{c}\text { Disc with surface crack: } \\
\begin{array}{c}a=0.34 \mathrm{~mm}, c=0.71 \mathrm{~mm} \\
a=0.76 \mathrm{~mm}, c=1.32 \mathrm{~mm} \\
a=1.5 \mathrm{~mm}, c=2.2 \mathrm{~mm}\end{array}\end{array}$}} \\
\hline & & & & & & & & & \\
\hline & & Elastic & Plastic & Creep & Damage & Elastic & Plastic & Creep & Damage \\
\hline \multirow{3}{*}{925} & 23 & + & + & - & - & + & + & - & - \\
\hline & 300 & + & + & + & + & + & + & + & + \\
\hline & 370 & + & + & + & + & + & + & + & + \\
\hline \multirow{3}{*}{1000} & 23 & + & + & - & - & + & + & - & - \\
\hline & 300 & + & + & + & + & + & + & + & + \\
\hline & 370 & + & + & + & + & + & + & + & + \\
\hline
\end{tabular}

Table 1: Various parameters employed in the numerical calculations.

The compressor disc considered for the numerical calculations was made of titanium alloy VT3-1. The main mechanical properties of the material analysed at three temperatures are summarized in Tab. 2, where, $\sigma_{0.2}-$ yield stress, $\sigma_{u t}-$ true ultimate tensile stress, $E$ - Young's modulus, $n$ - strain hardening exponent, $\alpha$ - strain hardening coefficient. 


\begin{tabular}{cccccc}
\hline $\begin{array}{c}\text { Temperature, } \\
{ }^{\circ} \mathrm{C}\end{array}$ & $\begin{array}{c}\sigma_{0.2} \\
\mathrm{MPa}\end{array}$ & $\begin{array}{c}\sigma_{\mathrm{ut}} \\
\mathrm{MPa}\end{array}$ & $\begin{array}{c}\mathrm{E} \\
\mathrm{GPa}\end{array}$ & $n$ & $\alpha$ \\
23 & 1004 & 1602 & 100 & 12.88 & 1.11 \\
300 & 753 & 1515 & 96 & 8.91 & 0.99 \\
370 & 699 & 1500 & 97 & 8.43 & 0.97 \\
\hline
\end{tabular}

Table 2: Summary of the main mechanical properties of titanium alloy VT3-1 at room and elevated temperatures.

The Norton law was used to describe a material's behaviour under the creep conditions:

$$
\dot{\varepsilon}_{c r}=B \cdot \sigma^{n}
$$

where $\dot{\varepsilon}_{c r}$ is the creep strain rate, $B$ is the creep coefficient, $n_{c r}$ is the creep exponent, and $\sigma$ is the stress. The creep properties for titanium alloy VT3-1 are listed in Tab. 3.

\begin{tabular}{ccccc}
\hline Material & $\begin{array}{c}\text { Temperature, } \\
{ }^{\circ} \mathrm{C}\end{array}$ & $\begin{array}{c}\text { Creep } \\
\text { equation }\end{array}$ & $\mathrm{B},(\mathrm{MPa})^{-\mathrm{n}}$ hour $^{-1}$ & $\mathrm{n}_{\mathrm{cr}}$ \\
& 300 & $\dot{\varepsilon}_{c r}=3 \cdot 10^{-9} \cdot \sigma^{1.6342}$ & $3 \cdot 10^{-9}$ & 1.6342 \\
VT3-1 & & & & \\
& 370 & $\dot{\varepsilon}_{c r}=1 \cdot 10^{-9} \cdot \sigma^{1.9337}$ & $10^{-9}$ & 1.9337 \\
\hline
\end{tabular}

Table 3: Creep properties of titanium alloy VT3-1 at $300^{\circ} \mathrm{C}$ и $370^{\circ} \mathrm{C}$.

In this study, the model proposed by Shlyannikov and Tumanov for the damage accumulation rate [12, 13] was used to assess the creep damage behaviour:

$$
\begin{aligned}
& \frac{d \omega}{d t}=\frac{\alpha b_{i}\left[(1-\chi) / \eta_{i}+\chi\right]^{n}}{t_{f}}\left(\frac{\sigma_{b}}{\sigma}\right)^{n} \frac{1}{(1-\omega)^{m}} \\
& b_{i}=\frac{2}{3} \sqrt{1-\xi+\xi^{2}} ; \xi=\frac{\lambda\left(1-v^{2}\right)-v(1+v)}{\left(1-v^{2}\right)-\lambda v(1+v)} ; \eta_{i}=\sqrt{1-\lambda+\lambda^{2}+v(v-1)(1+\lambda)^{2}}
\end{aligned}
$$

where $0 \leq \omega \leq 1$ is the measure of damage, with $\omega=0$ denoting the undamaged state and $\omega=1$ the fully damaged state; $\chi$ is the experimental material constant, which is determined as the ratio of uniaxial tensile strength to compression strength $\chi=\sigma_{t} / \sigma_{c}$. For brittle fracture $\chi=0$, whereas $\chi=1$ is for ductile fracture $t_{f}$ is the time for the fracture to occur under creep conditions, $m$ is the constant in the law of damage accumulation, $\lambda=\sigma_{2} / \sigma_{1}$ is the principal stress ratio, and $v$ is the Poisson's ratio. Eqn. (2) allows us to consider the complex stress state. Knowing only the constants of the Norton law equation and the time to fracture at least at one level of the effective nominal stresses is enough to determine the constants of Eqn. (2) [12,13]. Eqn. (2) was integrated into the ANSYS finite element (FE) code [14]. A full-field 3D FE analysis was conducted using the ANSYS code to determine the stress-strain state parameters of the GTE compressor disc with the considered geometry. 


\section{ELASTIC-PLASTIC STRESS FIELDS IN THE GTE COMPRESSOR DISC}

he first part of this study is concerned with the stress-strain state analysis of the compressor disc without cracks. FEM calculations were performed to determine the stress and strain distributions under different loading conditions within a specified temperature range. The 3D segment of the disc with blades was simulated due to the cyclic symmetry property of the disc. A 20-node quadrilateral isoparametric 3D solid FE model represented the 3D compressor disc configuration (Fig. 2). The displacements of the radial sections of the disc corresponded to the XOY, YOZ and XOZ planes and were limited under normal. The interaction between the blade root and the mounting holes of the disc was modelled using contact elements.

The 3D FE model of the aircraft GTE compressor disc D-36 are presented in Fig. 2a. The global elastic-plastic equivalent, von Mises stress distributions and local nonlinear strain zone in a compressor disc with an angular velocity of $925 \mathrm{rad} / \mathrm{s}$ at room temperature are shown in Figs. 2b and 2c.

a)
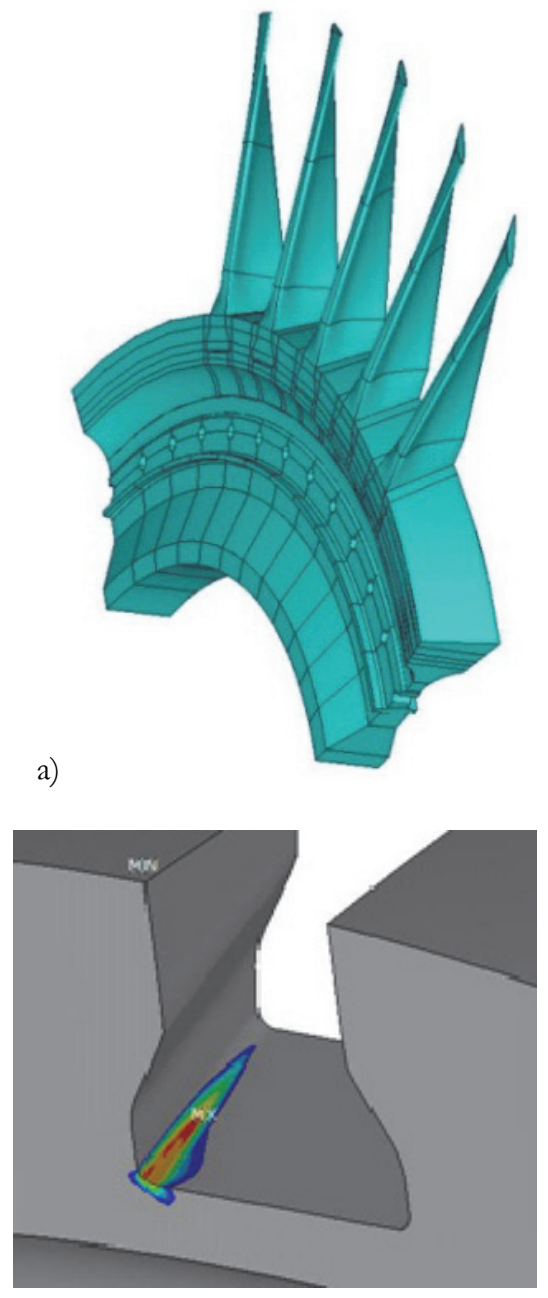

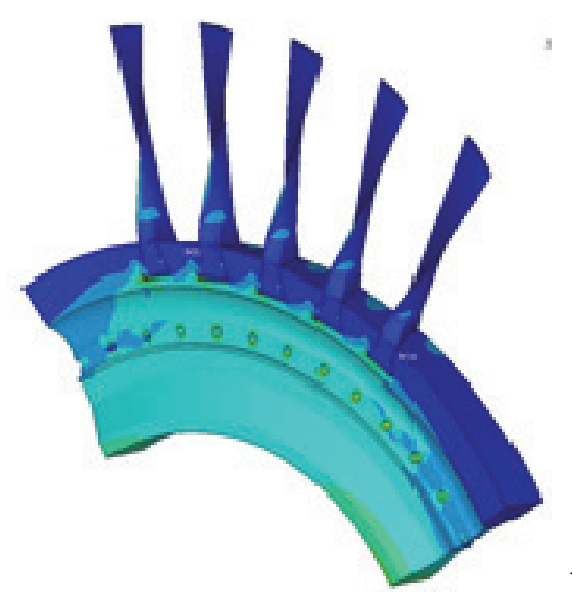

b)

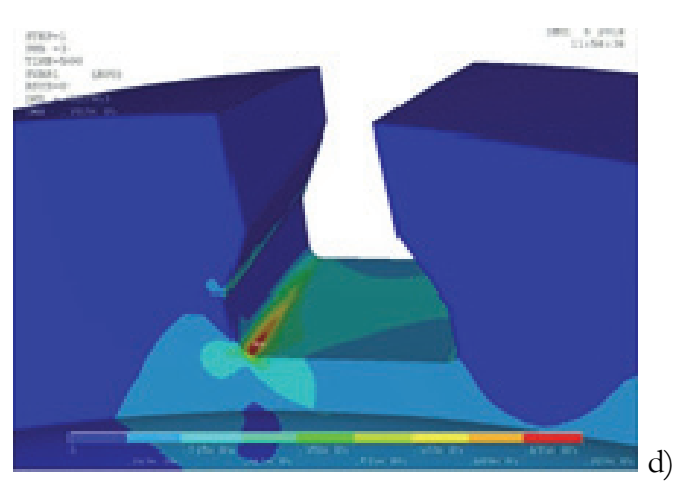

Figure 2: The 3D FE model (a), Global von Mises stress distributions (b), local nonlinear strains zone (c) and damage distribution (d) in aircraft GTE compressor disc.

Results indicated that the main high-loaded areas of the disc are the slot fillets under the blade in which the maximum stresses exceed the yield strength of the titanium alloy VT3-1 at the temperature considered. A similar pattern was observed for all other combinations of the angular velocity and temperatures listed in Tab. 1 . The stress and strain level in the disc depends on the temperature and the angular velocity. 
Fig. $2 \mathrm{~d}$ shows the damage field in the slot fillets of the compressor disc at $370^{\circ} \mathrm{C}$. An area of defect nucleation in the slot fillet was determined on the basis of the maximum value of the damage. This area coincides with the localization of real cracks occurring in the compressor disc during the operation. The obtained area of defect nucleation was used as a basis for the second part of the work.

\section{STRESS-STRAIN STATE OF THE GTE COMPRESSOR DISC WITH OPERATIONAL DAMAGES}

$\mathrm{T}$

he second part of the numerical study is concerned with the stress-strain state analysis of the GTE compressor disc with cracks. The location of the surface defect was chosen in accordance with the direction previously determined at the first stage of this study. The initial crack inclination (nearly $45^{\circ}$ ) was defined in a manner consistent with the results of the full-size compressor disc's experimental low cycle fatigue tests. The position of the quarter-elliptic crack fronts in the compressor disc and the size of the simulated defects are presented in Fig. 3. The crack was modelled as a notch with a crack tip curvature radius $r=0.002 \mathrm{~mm}$, where $a$ is the crack depth, and $c$ is the crack size on the free surface of the disc.

To compare the behaviour of the governing parameters along the corner quarter-elliptical crack front, we use normalized coordinates in the following forms:

$$
\begin{aligned}
& x=\Delta \phi \cos \phi, y=\Delta \phi \sin \phi \\
& x=\Delta \phi \cos \phi, y=\Delta \phi \sin \phi \\
& x_{i}=\Delta \phi \cos \phi_{i}, y_{i}=\Delta \phi \sin \phi_{i}, \phi_{i} \in\left[\phi_{0}, \phi_{c}\right], \Delta \phi=\phi_{c}-\phi_{0} \\
& \bar{X}_{i}=\frac{x_{0}-x_{i}}{x_{0}-x_{c}}, \quad \bar{Y}_{i}=\frac{y_{0}-y_{i}}{y_{0}-y_{c}} \\
& R_{i}=\frac{1}{\sqrt{2}} \sqrt{\bar{X}_{i}^{2}+\bar{Y}_{i}^{2}}, \quad R_{i} \in[0,1]
\end{aligned}
$$

where $\phi_{0}$ is an angle denoting the position of the crack front point on the free surface of the disc. $\phi_{c}$ is an angle that corresponds to the crack front point placed on the slot key's surface (Fig. 3). In this study, a dimensionless variable $R$ was used in a range from 0 to 1 , where $R=0.0$ indicates the exterior surface of the compressor disc (point $B$ ), and $R=1.0$ corresponds to the slot surface (point A).

Once the location of the crack and the size of the crack are identified, the region around the crack should be meshed appropriately to calculate the nonlinear fracture resistance parameters accurately. A quarter-elliptical part-though crack was inserted in the compressor disc FE model (Fig. 4) in the area of the disc and blade attachment.

A full-field 3D FE analysis was performed to obtain the stress and strain fields along the corner crack front in the compressor disc when subjected to different combinations of angular velocities, temperatures and crack front positions (Tab. 1).

Fig. 5 shows typical plots of the nonlinear strain zones along the curvilinear crack front in the compressor disc for plastic, creep and damage solutions. The nonlinear strain zone pertains to when the zone within the total strain intensity exceeds the yield strain value. Results show that under the operating loading conditions, the distribution of strains (Fig. 5) were non-symmetrical due to mode mixity, and the nonlinear zone was larger in the slot key relative to the free surface of the disc. The maximum value of strain intensity was located in the slot fillet's inner surface for all considered combinations of variable parameters and is presented in Tab. 1. The crack was assumed to grow primarily along the thickness of the disc. This assumption was confirmed by the data on the crack paths in the slot key fillet [8].

The nonlinear strain zone under creep conditions was significantly larger than that under the plastic solution. Strain intensity increased due to damages under creep conditions. Thus, an account the damages allows a more conservative estimate of the degradation of the material properties and stress-strain state parameters. 


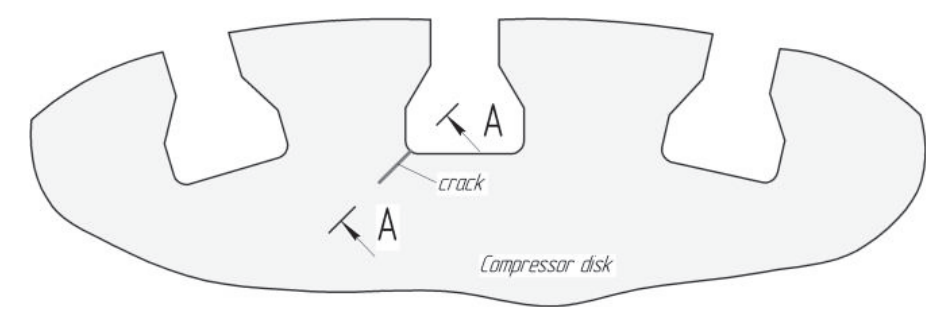

\begin{tabular}{ccc}
\hline & point & point \\
Crack front & A & B \\
& c, mm & a, mm \\
front 1 & 0.71 & 0.34 \\
front 2 & 1.32 & 0.76 \\
front 3 & 2.22 & 1.5 \\
\hline
\end{tabular}

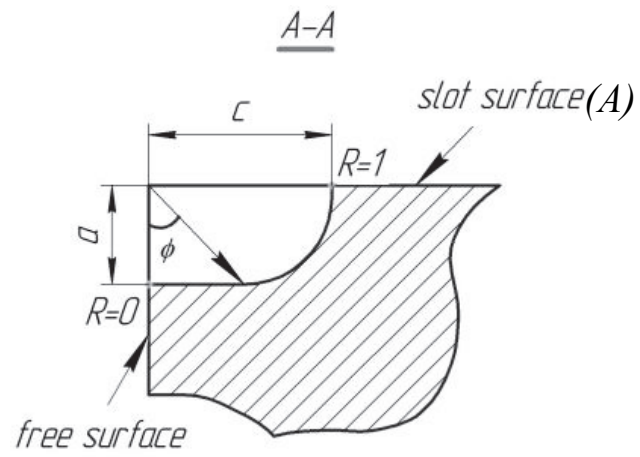

(B)

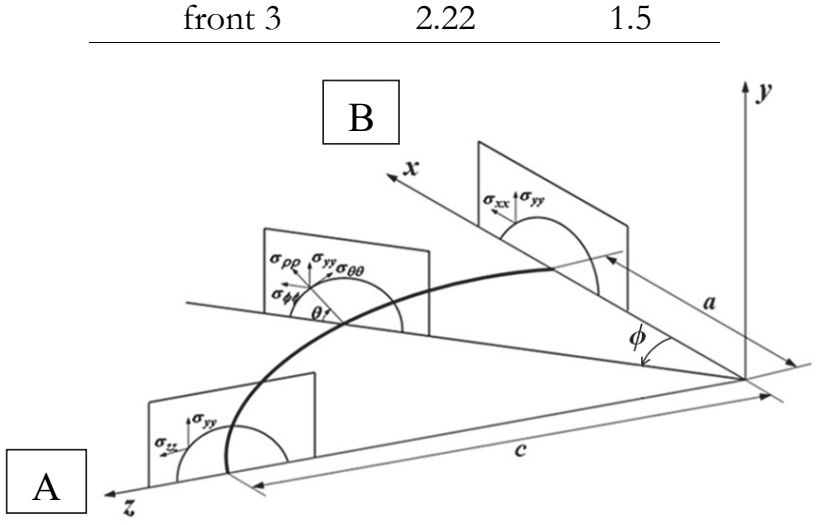

Figure 3: Crack front positions and sizes in the slot fillet of aircraft GTE compressor disc.
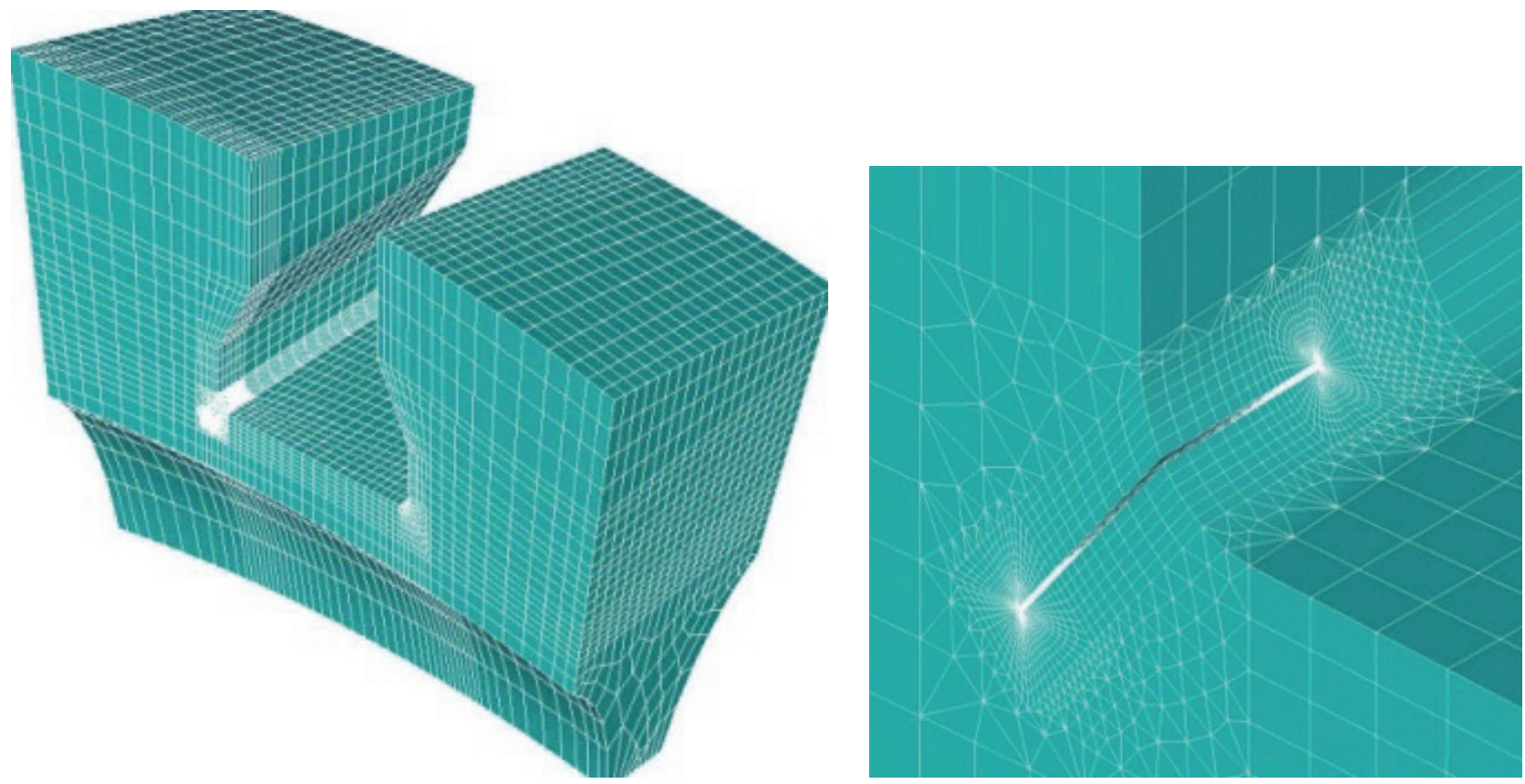

Figure 4: The 3D FE meshes of slot fillet of compressor disc with a quarter-elliptical part-though crack. 


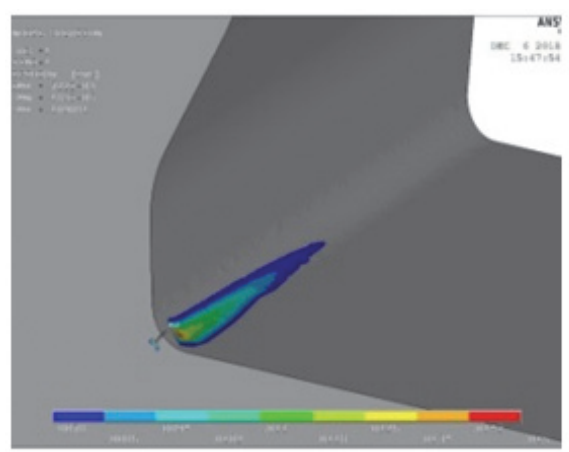

Plastic solution

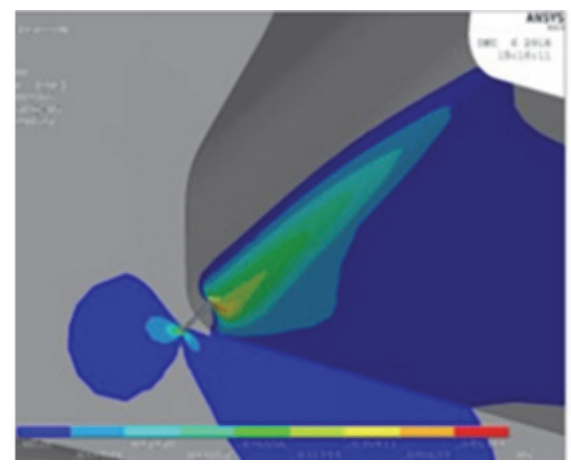

Creep

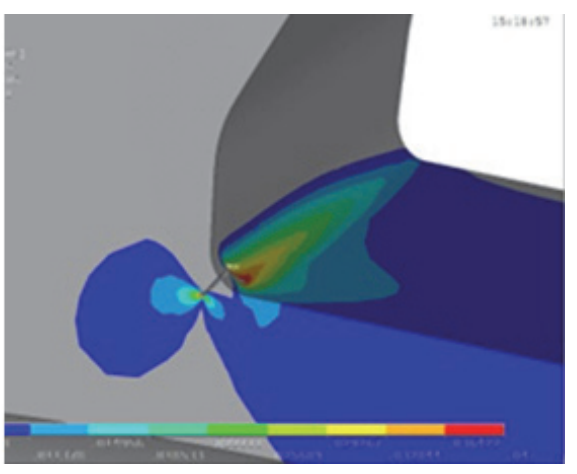

Damage

Figure 5: Strains intensity distributions in the compressor disc with a crack in a slot fillet.
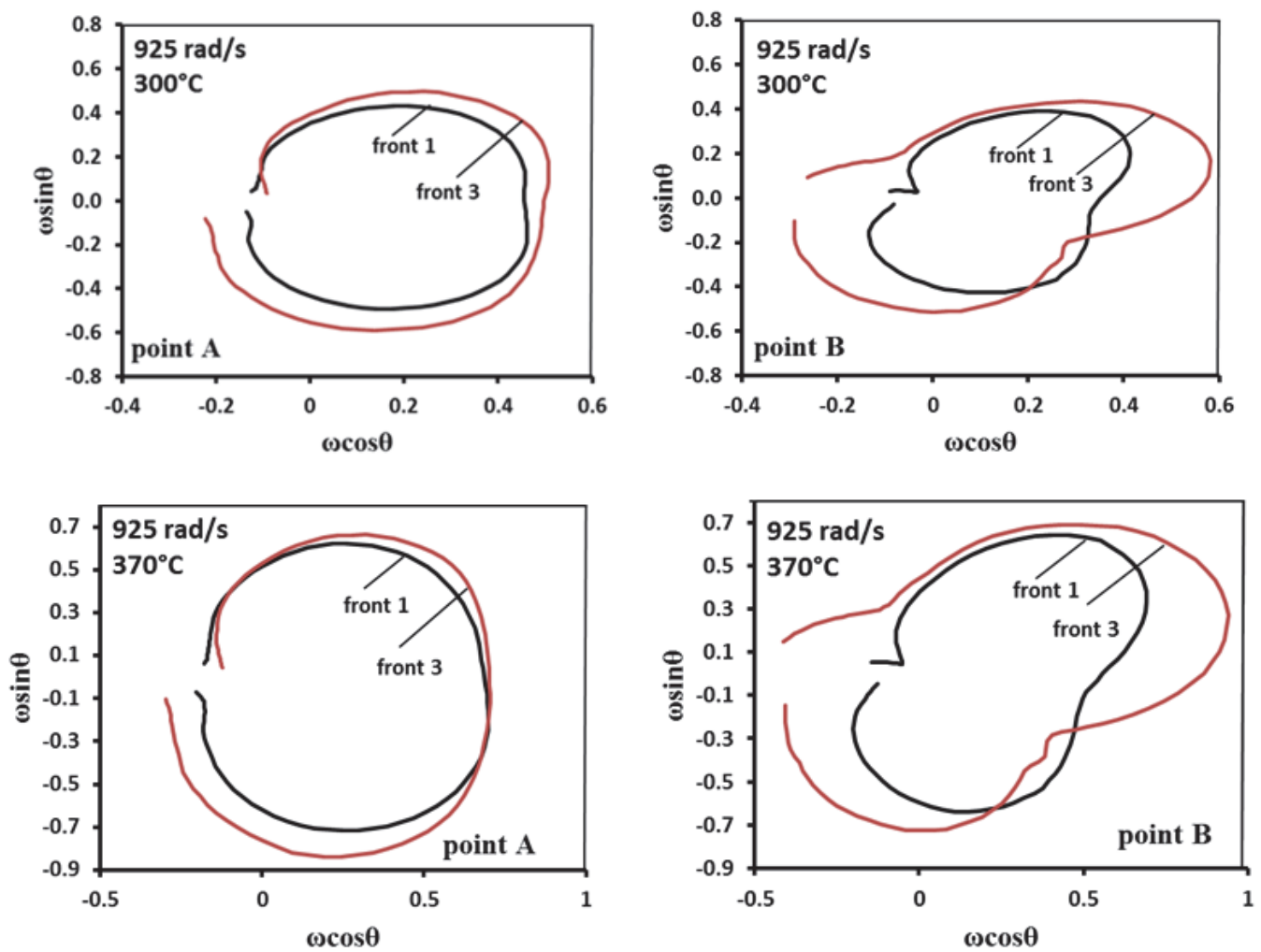

Figure 6: Contours of creep damage around crack tip on slot fillet surface (point A) and free surface (point B) of compressor disc with angular velocity $925 \mathrm{rad} / \mathrm{s}$.

Fig. 6 shows the contours of the damaged zones around the crack tip in the slot fillet of the compressor disc with an angular velocity of $925 \mathrm{rad} / \mathrm{s}$ at $300^{\circ} \mathrm{C}$ and $370^{\circ} \mathrm{C}$. Results are presented for two sections: the inner surface of the slot fillet (Fig. 3 point A) and the free surface of the disc (Fig. 3 point B). The crack front positions are indicated by the numbers 1 and 3 , respectively. The contours of the damaged zone for the second crack front occupied an intermediate position. As shown in Fig. 6, the measure of damage depended on the temperature, crack size and on the point along the crack front. The shape of the damage contours in the slot fillet and on the free surface (points A and B correspondingly) were significantly different. On the inner surface of the slot fillet, the damaged zone was close to symmetrical; meanwhile, substantial asymmetry was observed on the free surface of the disc. Moreover, the asymmetry of the damaged zone on the free surface increased with the increasing crack size. 


\section{NONLINEAR FRACTURE RESISTANCE AND CONSTRAINT PARAMETERS IN THE GTE COMPRESSOR DISC}

\section{Elastic and plastic stress intensity factors}

hlyannikov et al. [5] showed that the stress-strain state in the rotating disc obtained from FE calculations was - biaxial indicating that the structure around the slot fillets of the key was subjected to radial and tangential stresses. $\cup$ Stress biaxiality ratio $\eta=\sigma_{r} / \sigma_{\theta \theta}$ is a function of the current value of the disc radius and varies from $\eta=-0.27$ to $\eta=+0.29$ [3]. The data presented in Fig. 8 also indicates a mixed mode behaviour along the crack front in the compressor disc. Different from pure mode I, calculating the two fracture parameters was necessary to study the influence of the mixed mode loading conditions on fracture resistance parameters, namely, Modes I and II stress intensity factors (SIFs) $K_{I}$ and $K_{2}$. Shlyannikov [15] generalised the numerical method of calculating the geometry-dependent correction factors $Y_{1}$ and $Y_{2}$ for SIF $K_{I}$ and $K_{2}$ under mixed mode fracture. This study directly used the results of the FE solution for calculating SIF $K_{I}$ and $K_{2}$ ahead of the crack tip $\left(\theta=0^{\circ}\right)$ :

$$
\begin{aligned}
& K_{e q \nu}^{2}=\sqrt{\left(K_{1}^{2}+K_{2}^{2}\right)^{2}+4\left(K_{1} K_{2}\right)^{2}} \\
& K_{1}=\sigma_{\theta \theta}^{F E M} \sqrt{2 \pi r} \\
& K_{2}=\sigma_{r \theta}^{F E M} \sqrt{2 \pi r}
\end{aligned}
$$

where $\sigma_{i}^{F E M}$ represents the stresses obtained from the FE solution, and $r$ and $\theta-$ are the polar coordinates centred at the crack tip.

The plastic stress intensity factor was introduced in $[3,16-17]$ as the unified fracture resistance parameter for fatigue crack growth rate characterization. For the compressor disc, the plastic SIF $K_{p}$ in pure Mode I (or pure Mode II) can be expressed directly in terms of the corresponding elastic equivalent SIF $K_{\text {eqv. }}$ This is shown in [18]:

$$
\bar{K}_{P}=\left[\left(\frac{K_{e q \nu}}{\sigma_{y}}\right)^{2} \frac{(1+v)(1+\kappa)}{4 \alpha I_{n} w}\right]^{\frac{1}{n+1}}
$$

where $\kappa=3-4 v, v$ is the Poisson's ratio, $I_{n}$ is the governing parameter of the elastic-plastic stress-strain fields in the form of $I_{n}$ factor, $a$ and $n$ are the hardening parameters, $\sigma_{y}$ is the yield stress, and $w$ is the characteristic size (in this case, the width of key).

In the asymptotic HRR solution [19-21], the $I_{n}$ is dependent only on the plastic properties of the material, namely, the strain-hardening exponent $n$. Shih [22] modified the HRR solution for the plane strain problem and found that the $I_{n}$ becomes dependent on the mode mixing parameter $M_{p}$ under mixed mode, small-scale yielding,. Shlyannikov and Tumanov [16] developed a method to determine the $I_{n}$ factor. This method considers the influence of the specimen and crack geometry [16]:

$$
\begin{aligned}
& I_{n}^{F E M}\left(\theta, M_{p}, n,(a / w)\right)=\int_{-\pi}^{\pi} \Omega^{F E M}\left(\theta, M_{p}, n,(a / w)\right) d \theta \\
& \Omega^{F E M}\left(\theta, M_{p}, n,(a / w)\right)=\frac{n}{n+1}\left(\tilde{\sigma}_{e}^{n+1}\right)^{F E M} \cos \theta- \\
& -\left[\tilde{\sigma}_{r r}^{F E M}\left(\tilde{u}_{\theta}^{F E M}-\frac{d \tilde{u}_{r}^{F E M}}{d \theta}\right)-\tilde{\sigma}_{r \theta}^{F E M}\left(\tilde{u}_{r}^{F E M}+\frac{d \tilde{u}_{\theta}^{F E M}}{d \theta}\right)\right] \sin \theta- \\
& -\frac{1}{n+1}\left(\tilde{\sigma}_{r r}^{F E M} \tilde{u}_{r}^{F E M}+\tilde{\sigma}_{r \theta}^{F E M} \tilde{u}_{\theta}^{F E M}\right) \cos \theta .
\end{aligned}
$$


A detailed description of the governing parameter in the form of $I_{n^{-}}$-factor definition is given in [16]. It is shown that $I_{n^{-}}$ factor is sensitive to the constraint effects and can be used as constraint parameter.

Stressstrain fields under extensive creep can be written in terms of creep stress intensity factor $K_{c r}$ in the following form [23]:

$$
\bar{K}_{c r}=\frac{1}{\sigma_{0}}\left(\frac{C^{*}}{B I_{n}^{c r} L}\right)^{\frac{1}{n_{r r}+1}}
$$

where $B$ and $n_{c r}$ are creep constants, $I_{n}^{c r}$ is the governing parameter of the stress-strain fields for power-law creeping materials, and $\mathrm{C}^{*}$ is the $\mathrm{C}$-integral under extensive creep. Methods for determining $C$-integral at various creep stages and conditions are given in [23-26].

A numerical method was introduced by Shlyannikov [23] to determine the governing parameters of the creep-crack tip fields in terms of the $I_{n}$ integral for power-law creeping materials. This method can be also be used to analyse the creepdamaged material's fracture resistance characteristics. $K_{c r}$ is the most effective crack tip parameter in correlating the creepfatigue crack growth rates in power plant materials and can be used for practical purposes [23, 24].

\section{Constraint parameters distributions}

The stress-strain state analysis of the compressor disc with corner cracks should be performed taking into account inplane and out-of-plane constraint effects. Shlyannikov et al. [27, 28] showed that different traditional approaches which can successfully describe the in-plane constraint are inaccurate for describing 3D surface cracks. In [29], constraint parameters were analysed as a function of cyclic tension loading and temperature conditions. Characterization of the constraint effects in the present study was performed using the local stress triaxiality $h, T_{Z}$-factor, $I_{n}$-factor and $I_{n}^{c r}$ for specified combinations of crack sizes and loading conditions. All parameters were determined at the crack tip distance range of $\mathrm{r} / \mathrm{a}=0.01$, where the numerical solution provides a stabilised result.

A local parameter of the crack-tip constraint was proposed in [30] as a secondary fracture parameter because the validity of some concepts previously mentioned depends on the chosen reference field. This stress triaxiality parameter is described as follows:

$$
h=\sigma_{k k} /\left(3 \sqrt{\frac{3}{2} s_{i j} s_{i j}}\right)
$$

where $\sigma_{k k}$ and $s_{i j}$ are hydrostatic and deviatoric stresses, respectively. As the function of the first invariant of the stress tensor and the second invariant of the stress deviator, the stress triaxiality parameter is a local measure of the in-plane and out-of-plane constraint effects that is independent of any reference field.

The $T_{Z}$-factor [31] has been recognized to present a measure of the out-of-plane constraint and can be expressed as the ratio of the normal stress components:

$$
T_{z}=\frac{\sigma_{z z}}{\sigma_{x x}+\sigma_{y y}}
$$

where $v$ is the Poisson's ratio, $\sigma_{\text {z }}$ is the out-of-plane stress, and $\sigma \mathrm{xx}$ and $\sigma_{y y}$ are the in-plane stresses.

Fig. 7 depicts the effect of temperature on the constraint parameters for plastic and creep solutions. Results for two crack front positions (initial and final [front 1 and 3 , respectively]) are presented. The $T_{z}$-factor and stress triaxiality $b$ change in character along the crack tip from the free surface $(R=0)$ and across the mid-plane $(0<R<1)$ towards the slot surface $(R=1)$.

All considered factors, such as the crack front position, temperature and angular velocity, affect the constraint parameters. However, the crack front position has the most significant influence. Whilst crack size increases, qualitative and quantitative changes in constraint parameters distributions occur. This occurrence contrasts with temperature and angular 
velocity, which only produce a quantitative effect on $T_{z}$-factor and $h$. The $T_{z}$-factor under creep conditions is nearly independent on the temperature within the considered range.
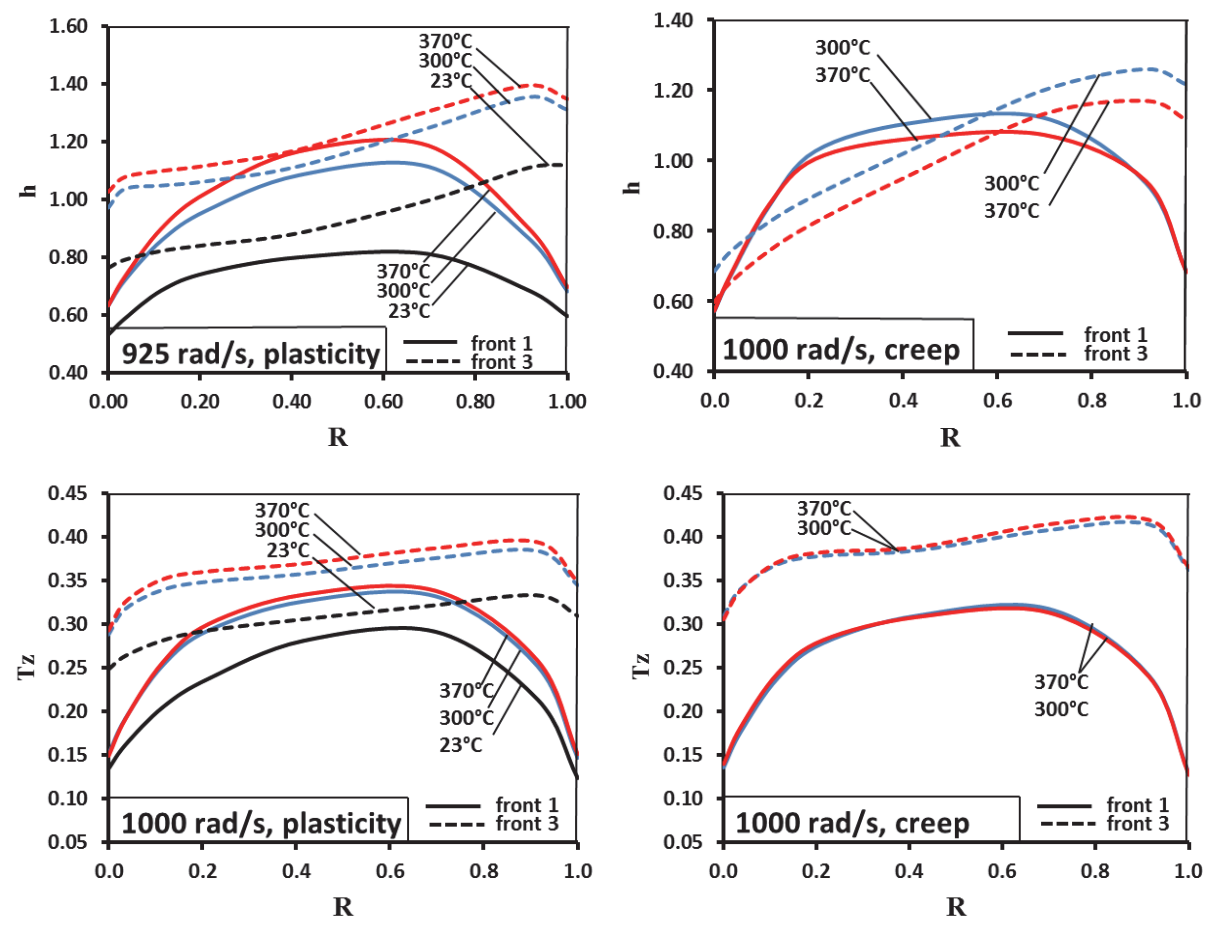

Figure 7: Distribution of $T_{z}$-factor and stress triaxiality $h$ along the crack for plastic solution and creep in the temperature range.

Fig. 8 demonstrates the behaviour of constraint parameters under creep conditions for the damaged and undamaged states. At the initial and intermediate crack front positions (front 1 and 2), the damage on both parameters considered in this section is insignificant. For the third crack front position, the damages lead to an unsubstantial increase in the $T_{z^{-}}$ factor and $h$.
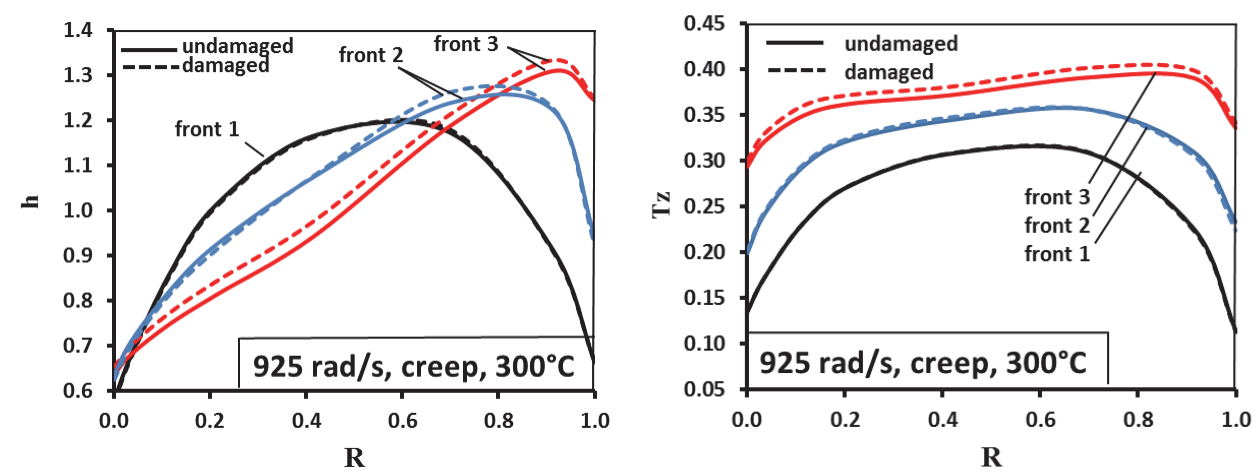

Figure 8: Impact of damage accounting on the constraint parameters behavior under creep conditions.

Thus, the $T_{z}$-factor and $b$ mainly reproduce the influence of crack front shape and position. The influence of loading conditions, temperature and damage of material is insignificant to these parameters.

The governing parameters of the elastic-plastic stress field $I_{n}$ and creep field $I_{n}^{c r}$ distributions along the cracked front in the compressor disc with an angular velocity of $1000 \mathrm{rad} / \mathrm{s}$ are plotted in Fig. 9. These distributions correspond to the different temperatures and crack front positions. The $I_{n}$-factor distributions are plotted against the normalized coordinates, where $R=0.0$ is the free surface, and $R=1.0$ is the inner surface of slot fillet. As shown in Fig. 9, the $I_{n^{-}}$ factor distributions essentially change along the crack front from the free surface towards the slot key. Material properties 
relating to temperature and the crack front position have a significant influence on the distribution of the $I_{n}$ and $I_{n}^{c r}$ factors.
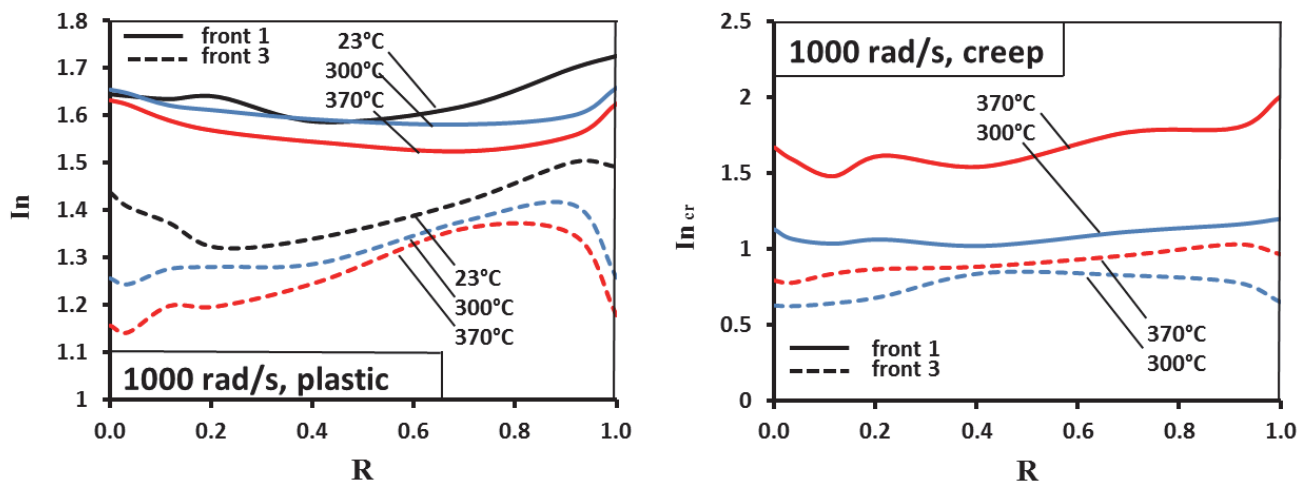

Figure 9: $I_{n}$ and $I_{n}^{c r}$-factors distributions along the crack front in the temperature range.
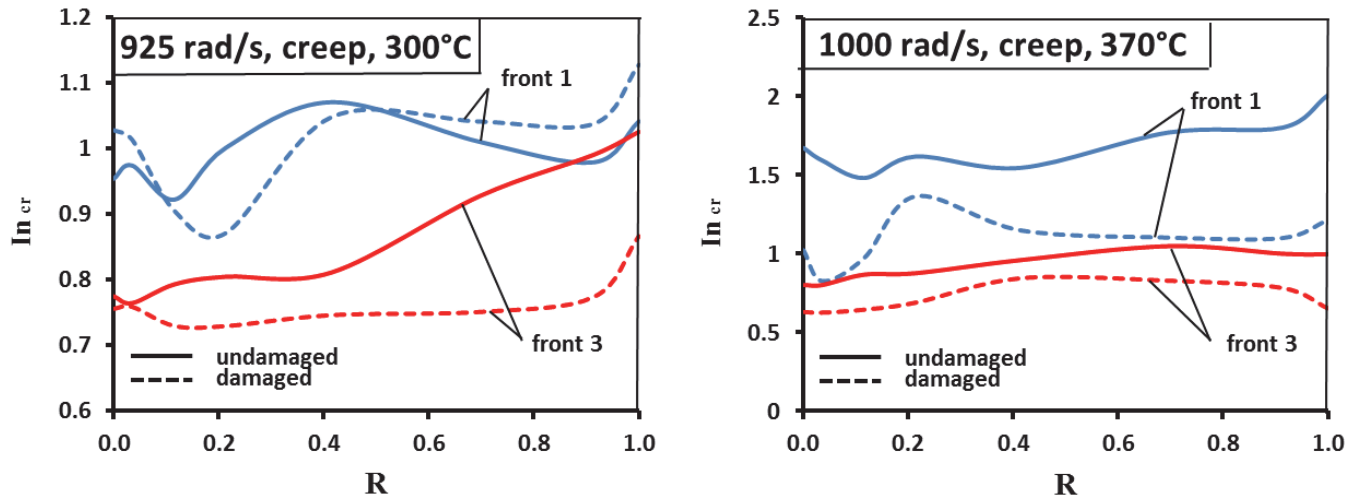

Figure 10: Impact of damage accounting on the $I_{n}^{\text {cr }}$-factor behavior.

The behaviour of the $I_{n}^{c r}$-factor for damaged and undamaged states is depicted in Fig. 10. In contrast to the traditional constraint parameters $T_{z}$ and $h$ (Fig. 8), the $I_{n}^{c r}$-factor is a function of the damage for all crack front positions, loading conditions and temperatures in the present study. Damage accounting under creep conditions causes changes in the $I_{n}^{c r}$ factor distributions for all the loading conditions and temperature combinations considered in this work. The $I_{n}^{c r}$-factor, which is used as the foundation for the creep stress intensity factor, is sensitive to in-plane and out-of-plane constraint effects. Moreover, the $I_{n}^{c r}$-integral has advantages over the traditional constraint parameters considered in this study due to sensitivity to damage accumulation.

\section{Elastic and plastic stress intensity factors distributions}

The behaviour of the elastic SIFs along the crack front in the GTE compressor disc under the considered loading conditions is shown in Fig. 9. The elastic SIFs change moderately as a result of the crack front position and angular velocity. At the same time, the elastic SIF is not sensitive to temperature. For each considered crack front position, the same $K_{\text {eqv }}$ distribution corresponds to three temperature values $\left(20^{\circ} \mathrm{C}, 300^{\circ} \mathrm{C}, 370^{\circ} \mathrm{C}\right)$. This fact imposes significant restrictions on the use of the elastic stress intensity factor as a fracture resistance parameter.

Fig. 12 depicts the plastic stress intensity factor distributions along the crack front for different combinations of angular velocity, temperature and crack front position. Plastic SIF, as well as elastic SIF, depend on the crack front position and angular velocity. However, in contrast to the elastic SIF, the nonlinear SIF $K_{P}$ is sensitive to the main material properties as a function of the compressor disc's operating temperature. Moreover, a significant change in $K_{p}$ is observed when the temperature rises from $20^{\circ} \mathrm{C}$ to $300^{\circ} \mathrm{C}$. A further increase in temperature of up to $370^{\circ} \mathrm{C}$ has no substantial effect on the distribution of the plastic stress intensity factor. 

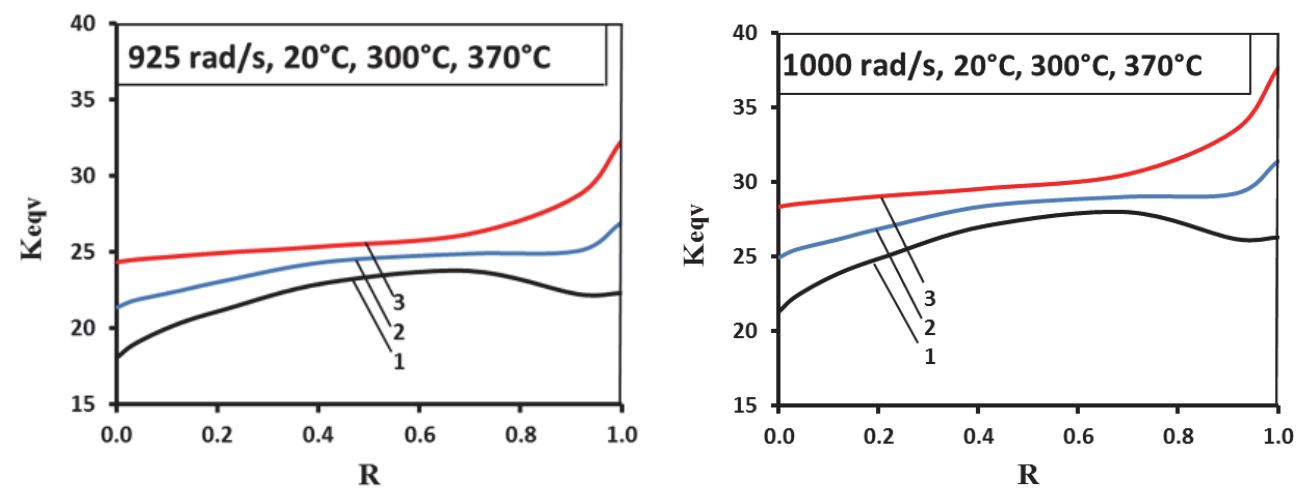

Figure 11: Elastic equivalent SIF $K_{\text {eqv }}$ distribution along the crack front in the temperature range. $(1$ - initial, 2 - intermediate, 3 - final crack fronts)
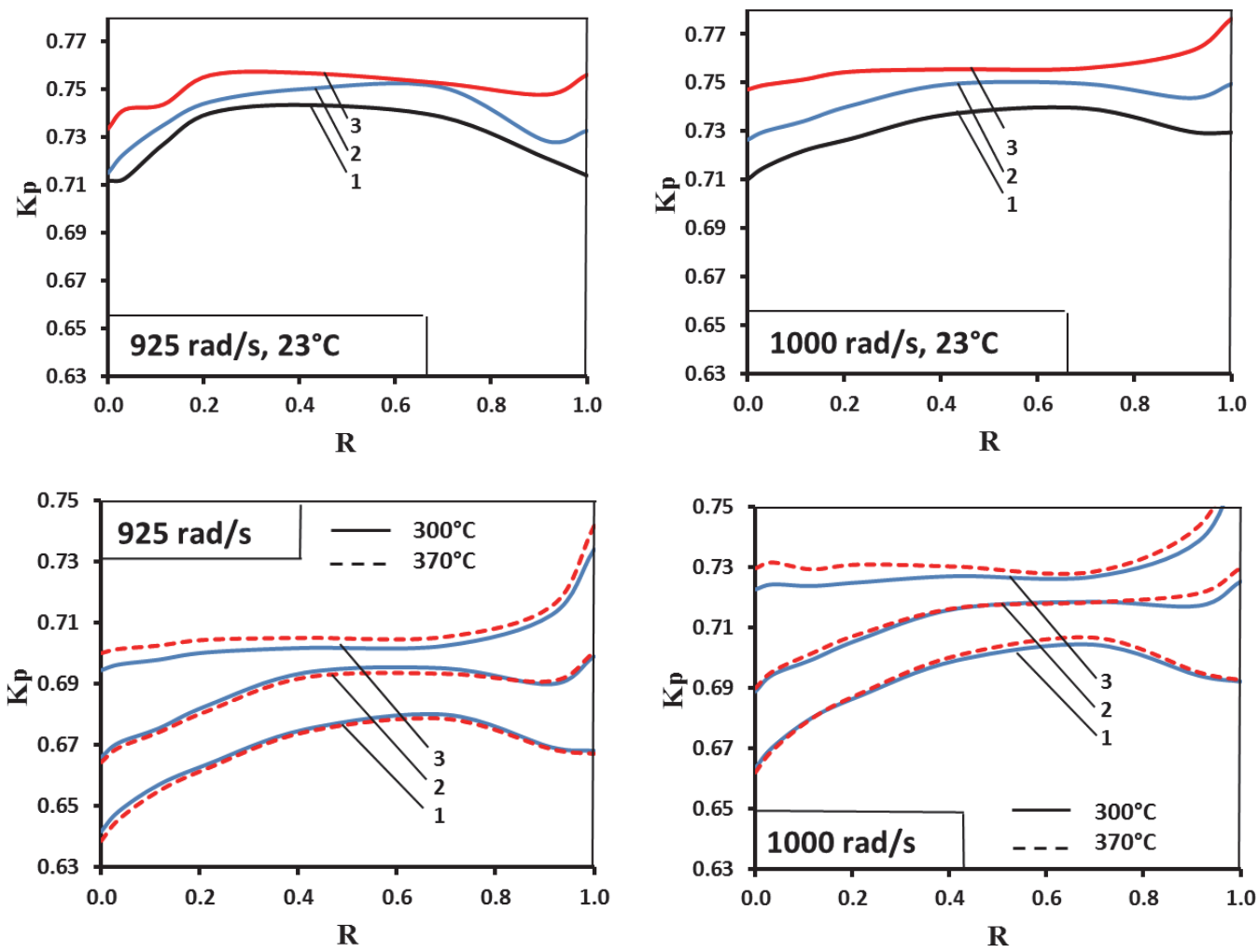

Figure 12: Plastic SIF $K_{p}$ distribution along the crack front in the temperature range. (1 - initial, 2 - intermediate, 3 - final crack fronts)

As previously mentioned, loading conditions (namely the angular velocity) affect the distribution of the plastic stress intensity factor; however, the results presented in Fig. 12 show that material properties related to temperature have a decisive influence on the $K_{p}$ value. These findings support the use of plastic SIF as a useful parameter for the assessment of the fracture resistance of materials and structures.

Creep stress intensity factor distributions for two values of the disc rotational speed and temperature for damaged and undamaged states are shown in Fig. 13. The factors considered in this work have a significant influence on the $K_{c r}$ distributions; these factors include angular velocity, temperature, crack size and position of the cross section in the disc. As shown in the presented data, $K_{c r}$ is sensitive to accumulated damage. Damage accounting leads to an increase in the nonlinear creep stress intensity factor, thus allowing the researchers to conclude that damage accounting provides an opportunity to perform an objective carrying capacity assessment. These results support the use of the creep SIF as a parameter for the assessment of the fracture resistance of materials and structures under high temperature conditions. 

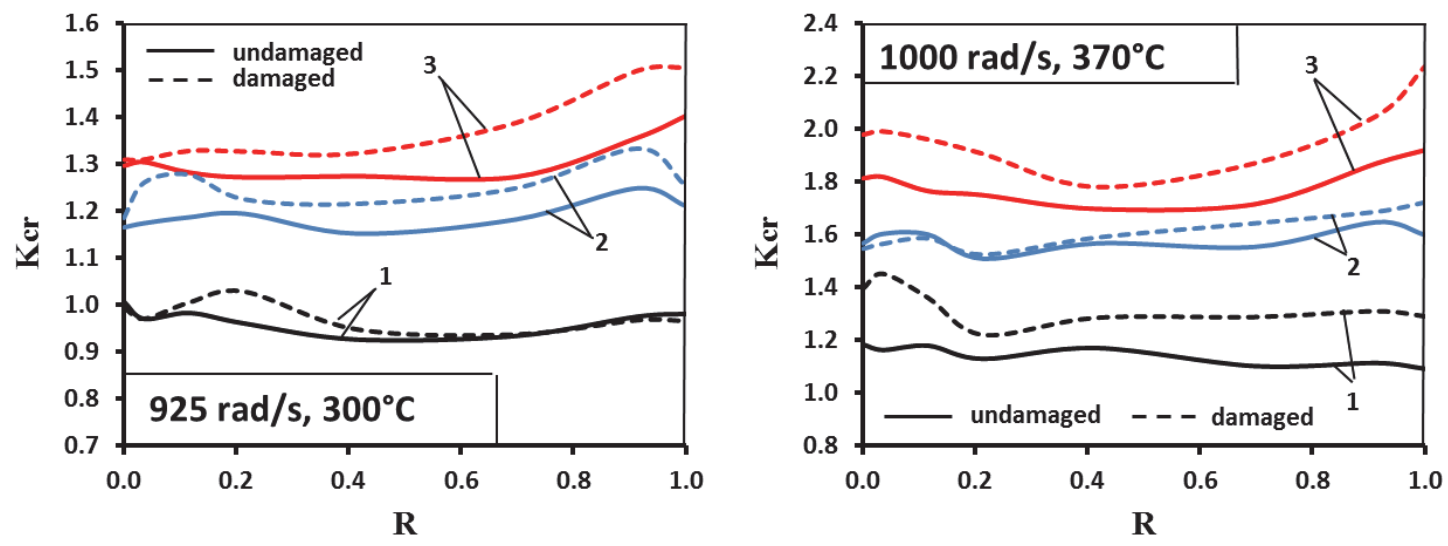

Figure 13: Creep SIF $K_{\text {or }}$ distribution along the crack front in the temperature range taking into account damage accumulation. $(1-$ initial, 2 - intermediate, 3 - final crack fronts).

\section{CONCLUSIONS}

$\mathrm{I}$ $\mathrm{n}$ this study, a numerical analysis of an aircraft GTE compressor disc was conducted under operation loading conditions taking into account damage accumulation. Different combinations of disc rotation angular velocity, operating temperature, quarter elliptical crack form and size and elastic-plastic properties of the titanium alloy VT3-1 were compared.

The constraint parameters in the form of the $T_{z}$-factor, local stress triaxiality $h$ and $I_{n}$ and $I_{n}^{c r}$-factor were analysed for the specified combinations of crack sizes and temperature conditions. The $I_{n}^{r r}$-factor, used as the foundation of the creep stress intensity factor, is sensitive to damage accumulation.

The distributions of the governing parameters for the crack tip were represented along the crack front in the form of elastic, plastic and creep SIFs. A study under creep conditions were carried out taking into account the damage of material, revealing that elastic SIF is not sensitive to temperature. The principal advantage of the plastic and creep stress intensity factors is its sensitivity to real material properties and temperature. Damage accounting provides an opportunity to perform an objective carrying capacity assessment. Nonlinear SIFs are found to be attractive as a self-dependent unified parameter for the characterisation of fracture resistance under room and elevated temperatures.

Based on the obtained numerical results of the present study, an ongoing work of the author will include crack growth rate and lifetime prediction.

\section{REFERENCES}

[1] Makhutov, N.A., Vorobyev, A.Z., Gadenin M.M. at al. (1983). Prochnost' konstrukcij pri malociklovom nagruzhenii, Moscow: Nauka, 272p.

[2] Zharoprochnye splavy dlja gazovyh turbin, edited by Shalin R.E. (1981). Moscow: Metallurgija, 479 p.

[3] Shlyannikov, V.N., Zakharov, A.P., Yarullin, R.R. (2016). Structural integrity assessment of turbine disk on a plastic stress intensity factor basis, International Journal of Fatigue, 92 (part 1), pp. 234-245.

DOI: $10.1016 /$ j.ijfatigue.2016.07.016.

[4] Kumar, R., Ranjan, V., Kumar, B., Ghoshal, S.K. (2018). Finite element modelling and analysis of the burst margin of a gas turbine disc using an area weighted mean hoop stress method, Engineering Failure Analysis, 90, pp. 425-433. DOI: $10.1016 /$ j.engfailanal.2017.12.014.

[5] Shlyannikov, V.N., Iltchenko, B.V., Stepanov, N.V. (2001). Fracture analysis of turbine disks and computationalexperimental background of the operational decisions, Engineering Failure Analysis, 8 (5), pp. 461-475. DOI: 10.1016/S1350-6307(00)00041-8.

[6] Shlyannikov, V.N., Yarullin, R.R., Zakharov, A.P. (2015). Fatigue life of power steam turbine disk material after loading history, Transactions of Academenergo, 3, pp. 78-91. 
[7] Papanikos, P., Meguid, S.A., Stjepanovic, Z. (1998). Three-dimensional nonlinear finite element analysis of dovetail joints in aeroengine discs, Finite Elements in Analysis and Design, 29, (3-4), pp. 173-186.

DOI: 10.1016/S0168-874X(98)00008-0.

[8] Shanyavsky, A.A., Stepanov, N.V. (1995). Fractographic analysis of fatigue crack growth in engine compressor disks of Ti-6Al-3Mo-2Cr titanium alloy, Fatigue \& Fracture of Engineering \& Material Structures, 18 (5), pp. 539-550. DOI: $10.1111 /$ j.1460-2695.1995.tb01416.x.

[9] Farrahi, G.H., Tirehdast, M., Masoumi Khalil Abad, E., Parsa, S., Motakefpoor, M. (2011). Failure analysis of a gas turbine compressor, Engineering Failure Analysis, 18 (1), pp. 474-484. DOI: 10.1016/j.engfailanal.2010.09.042.

[10] Giannella, V., Citarella, R., Perrella, M., Shlyannikov. V. (2019). Surface crack modelling in an engine compressor disc, Theoretical and Applied Fracture Mechanics, in press. DOI: 10.1016/j.tafmec.2019.102279 .

[11] Shaniavski, A.A. (2003). Tolerance fatigue failures of aircraft components. Synergetics in engineering applications. In: Monography, Ufa, pp. 803

[12] Shlyannikov, V.N., Tumanov, A.V. (2018). Force and deformation models of damage and fracture during creep, Physical mesomechanics, 3, pp.70-85.

[13] Shlyannikov, V.N., Tumanov, A.V. (2018). Creep fracture resistance parameters determination based on stress and ductility damage models, Fatigue \& Fracture of Engineering \& Material Structures, 41 (10), pp. 2110-2129. DOI: $10.1111 /$ ffe. 12766.

[14] ANSYS. Theory Reference. 001242. Eleventh Edition. (1999). SAS IP Inc.

[15] Shlyannikov, V.N. (2013). T-stress for crack paths in test specimens subject to mixed mode loading. Engineering Fracture Mechanics, 108, pp. 3-18. DOI: 10.1016/j.engfracmech.2013.03.011.

[16] Shlyannikov, V.N., Tumanov, A.V. (2014). Characterization of crack tip stress fields in test specimens using mode mixity parameters, International Journal of Fracture, 185, pp. 49-76. DOI: 10.1007/s10704-013-9898-0.

[17] Shlyannikov, V.N., Tumanov, A.V., Zakharov, A.P. (2014). The mixed mode crack growth rate in cruciform specimens subject to biaxial loading, Theoretical and Applied Fracture Mechanics, 73, pp. 68-81. DOI: $10.1016 /$ j.tafmec.2014.06.016.

[18] Shlyannikov, V.N., Zakharov, A.P. (2017). Generalization of Mixed Mode Crack Behaviour by the Plastic Stress Intensity Factor, Theoretical and Applied Fracture Mechanics, 91, pp. 52-65. DOI: 10.1016/j.tafmec.2017.03.014 .

[19] Hutchinson, J.W. (1968). Plastic stress and strain fields at a crack tip, Journal of Mechanics and Physics of Solids, 16, pp. 337-347.

[20] Rice, J.R., Rosengren, G.F. (1968). Plane strain deformation near a crack tip in a power-law hardening material, Journal of Mechanics and Physics of Solids, 16, pp. 1-12.

[21] Hutchinson, J.W. (1968). Singular behaviour at the end of a tensile crack in a hardening material, Journal of Mechanics and Physics of Solids, 16, pp. 13-31.

[22] Shih, C.F. (1974). Small-Scale Yielding Analysis of Mixed Mode Plane-Strain Crack Problems, Fracture Analysis, ASTM Special Technical Publications, 560, pp.187-210.

[23] Shlyannikov, V.N., Tumanov, A.V., Boychenko, N.V. (2015). A creep stress intensity factor approach to creep-fatigue crack growth, Engineering Fracture Mechanics, 142, pp. 201-219. DOI: 10.1016/j.engfracmech.2015.05.056.

[24] Shlyannikov, V.N., Tumanov, A.V., Boychenko, N.V. (2018). Creep-fatigue crack growth rate assessment using ductility damage model, International Journal of Fatigue, 116, pp.448-461. DOI: 10.1016/j.ijfatigue.2018.07.003.

[25] Boychenko, N.V. (2017). Parameters of cracked bodies behavior under creep conditions, Transactions of Academenergo, 1, pp. 104-118.

[26] Saxena, A. (1998). Nonlinear fracture mechanics for engineers. Boca Raton, FL, CRC Press.

[27] Shlyannikov, V.N., Tumanov, A.V., Zakharov, A.P., Gerasimenko, A.A. (2016). Surface flaw behavior under tension, bending and biaxial cyclic loading, International Journal of Fatigue, 92 (part 2), pp.557-576. DOI: 10.1016/j.ijfatigue.2016.05.003.

[28] Slyannikov, V.N., Yarullin, R.R., Ishtyryakov, I.S. (2015). Surface crack growth in cylindrical hollow specimen subject to tension and torsion, Frattura ed Integrità Structurale, 33, pp.335-344. DOI: 10.3221/IGF-ESIS.33.37.

[29] Yarullin, R.R., Ishtyryakov, I.S. (2016). Fatigue Surface Crack Growth in Aluminum Alloys under Different Temperatures. Procedia Engineering, 160, pp.199-206. DOI: 10.1016/j.proeng.2016.08.881.

[30] Henry, B.S., Luxmoore, A.R. (1997). The Stress Triaxiality Constraint and the Q-value as Fracture Parameter, Engineering Fracture Mechanics, 57, pp.375-390. DOI: 10.1016/S0013-7944(97)00031-3.

[31] Guo, W.L. (1993). Elastoplastic three dimensional crack border field-I,II, Engineering Fracture Mechanics, 46, pp.93113. DOI: 10.1016/0013-7944(93)90306-D. 